\title{
COMPARISON OF EPIDURAL BUPIVACAINE AND BUPIVACAINE-MAGNESIUM SULPHATE COMBINATION IN LOWER ABDOMINAL SURGERIES
}

\author{
Pichai Lenin'1, Pachaimuthu Elango ${ }^{2}$, Gurusamy Sivakumar³, Anbu Srinivasan ${ }^{4}$ \\ ${ }^{1}$ Senior Assistant Professor, Department of Anaesthesiology, Government Thiruvarur Medical College \& Hospital, Thiruvarur. \\ 2Professor, Department of Anaesthesiology, KAP Viswanatham Government Medical College/MGM Govt. Hospital, Tiruchirapalli. \\ ${ }^{3}$ Professor, Department of Anaesthesiology, KAP Viswanatham Government Medical College/MGM Govt. Hospital, Tiruchirapalli. \\ ${ }^{4}$ Associate Professor, Department of Orthopaedics, KAP Viswanatham Government Medical College/MGM Govt. Hospital, Tiruchirapalli.
}

\section{ABSTRACT}

\section{BACKGROUND}

The epidural technique became popular as it has some specific advantages over spinal anaesthesia. The feasibility of extended duration and differential blockade extended its application into other fields like post-operative analgesia, chronic pain relief and obstetric pain relief. But some inherent negative points of epidural technique like delayed onset and patchy analgesia persist. Various attempts have been made to rectify these negative points. Analgesic effects of magnesium sulphate on peripheral nerves may be due to the antagonism of NMDA receptors, thus preventing central sensitisation from peripheral nociceptive stimulation. Also, magnesium competitively blocks calcium influx into presynaptic endings leading to reduced acetylcholine release. The aim of the study is to add magnesium sulphate as an adjunct to epidural Bupivacaine and evaluate the impact of magnesium sulphate on the quality of the block using the following parameters; Onset of sensory blockade, Motor blockade quality, two segment regression time, Post-operative analgesia and Impact of magnesium sulphate on haemodynamic changes.

\section{MATERIALS AND METHODS}

We conducted a double blinded randomised controlled study in 100 patients belonging to ASA I and II undergoing elective lower abdominal surgeries to evaluate the effect of adding magnesium sulphate to Bupivacaine alone in epidural anaesthesia in KAPV Govt. Medical College Hospital. For the same reason, we divided randomly the patients into two groups of 50 each. Group $\mathrm{C}$ received $19 \mathrm{~mL}$ of $0.5 \%$ of Bupivacaine ( $95 \mathrm{mg}$ ) and $1 \mathrm{~mL}$ of normal saline. Group S received $19 \mathrm{~mL}$ of $0.5 \%$ of Bupivacaine ( $95 \mathrm{mg}$ ) and $1 \mathrm{~mL}$ of magnesium sulphate $(50 \mathrm{mg})$. The total volume of the injected solution was $20 \mathrm{~mL}$ in both groups.

\section{RESULTS}

We found the onset of sensory blockade was faster in the magnesium group ( $p$ value $<0.0001$ ). The duration of post-operative analgesia was slightly prolonged in the study group ( $p$ value 0.41 ). The incidence of side effects was similar in both the groups.

\section{CONCLUSION}

In our study, we found the onset of sensory blockade was faster in the magnesium group. The duration of post-operative analgesia was slightly prolonged in the study group. This study concludes that epidural magnesium sulphate when added to Bupivacaine will shorten the onset of sensory blockade significantly in patients undergoing elective lower abdominal surgeries without increasing the incidence of side effects.

\section{KEYWORDS}

Epidural Analgesia, Bupivacaine, Magnesium Sulphate, Onset of Analgesia, Postoperative Analgesics.

HOW TO CITE THIS ARTICLE: Lenin P, Elango P, Sivakumar G, et al. Comparison of epidural bupivacaine and bupivacainemagnesium sulphate combination in lower abdominal surgeries. J. Evolution Med. Dent. Sci. 2017;6(69):4925-4929, DOI: 10.14260/Jemds/2017/1068

\section{BACKGROUND \\ The epidural analgesia technique became popular as it has some specific advantages over spinal anaesthesia. The feasibility of extended duration and differential blockade extended its application into other fields like post-operative analgesia, chronic pain relief and obstetric pain relief. But some inherent negative points of epidural technique like delayed onset and patchy analgesia persist. Various attempts have been made to rectify these negative points.}

Financial or Other, Competing Interest: None.

Submission 13-07-2017, Peer Review 15-08-2017,

Acceptance 21-08-2017, Published 28-08-2017.

Corresponding Author:

Dr. Pachaimuthu Elango.

D 49, $10^{\text {th }}$ Cross West,

Thillai Nagar, Trichy- 600018.

E-mail: narmadha18@yahoo.com

DOI: $10.14260 /$ jemds $/ 2017 / 1068$
Various additive drugs have been tried along with local anaesthetics in an attempt to hasten the onset of blockade to improve the quality of block.

Among the drugs that have been tried, magnesium sulphate deserves special mention. Even though magnesium sulphate has been used for various other purposes, its entry into anaesthetic armamentarium is new. Magnesium sulphate has been described to possess various properties. The potentiation of local anaesthetic drugs is one among them. Hence our study aims to evaluate the effect of its addition to local anaesthetic in epidural blockade.

Magnesium is the fourth most plentiful cation in the body. It has antinociceptive effects in animal and human models of pain. ${ }^{1,2}$ These effects are primarily based on the regulation of calcium influx into the cell, that is, natural physiological calcium antagonism and antagonism of N-methyl-D-aspartate (NMDA) receptor. It has been reported that intrathecal magnesium enhances opioid antinociception in an acute incisional model. ${ }^{2}$ These effects have prompted the 
investigation of magnesium as an adjuvant for postoperative analgesia. ${ }^{2}$ There are studies concerned with different routes of administration such as intravenous or intrathecal that improve anaesthetic and analgesic quality.3,4 Magnesium sulphate, a potent antagonist of NMDA receptors, when used epidurally is claimed to hasten the onset of sensory blockade. Magnesium also causes physiological Calcium channel blockade and decreases the postoperative opioid requirements. ${ }^{5}$ Analgesic effects of magnesium sulphate on peripheral nerves may be due to the antagonism of NMDA receptors thus preventing central sensitisation from peripheral nociceptive stimulation. ${ }^{6}$ Also, magnesium competitively blocks calcium influx into presynaptic endings leading to reduced acetylcholine release. ${ }^{7}$ The surface charge theory is another possible mechanism. ${ }^{6}$ Peripheral nerve blockade due to local anaesthetics may be enhanced by modulation of the external magnesium concentration bathing a nerve bundle. Moreover, the high concentration of $\mathrm{Mg}^{2+}$ attracted by the negative charges of the outer membrane surface affected $\mathrm{Na}^{+}$channel gating and could cause hyperpolarisation and inhibition of nerve conduction. ${ }^{8}$

\section{Aim}

Sole epidural Bupivacaine is becoming unpopular due to delayed onset of sensory blockade. The aim of the study is to add magnesium sulphate as an adjunct to epidural Bupivacaine and evaluate the impact of magnesium sulphate on the quality of the block using the following parameters; Onset of sensory blockade, Motor blockade quality, two segment regression time, Post-operative analgesia and Impact of magnesium sulphate on haemodynamic changes.

\section{MATERIALS AND METHODS}

We conducted a double blinded randomised controlled study in 100 patients belonging to ASA I and II undergoing elective lower abdominal surgeries to evaluate the effect of adding magnesium sulphate to Bupivacaine and Bupivacaine alone in epidural anaesthesia in KAP Viswanatham Govt. Medical College/MGM Govt. Hospital. This study was conducted in Department of Anaesthesiology, Govt. KAP Viswanatham Medical College/MGM Govt. Hospital, Trichy during 20092011. According to a study by T Ghatak et al, ${ }^{9}$ the sample size calculation: For testing two independent means Mean1 = 18.73, SD1 $=2.79$, Mean2 $=16.93$, SD2 $=3.43$, Ratio $(\mathrm{n} 2 / \mathrm{n} 1)=$ 1 , Alpha $=0.05, \mathrm{Z}(0.975)=1.959964$, Beta $=0.20, \mathrm{Z}(0.80)=$ 0.8416212 , Sample size: group $1=48$, group $2=48$. For the same reason, we divided randomly the patients into two groups of 50 each. Block randomization technique used to allocate the patients to epidural Bupivacaine and Bupivacaine Magnesium sulphate combination group. Blocks of varying sizes ranging from $2-6$ used for block randomisation.

After approval of the study by our institutional ethics committee, the study was conducted on 100 ASA grade I or II patients undergoing elective lower abdominal surgeries. Informed consent was obtained from all patients. Lumber epidural anaesthesia was performed in all the patients. Age of the patients ranged from 23-70 years and weighing 45-80 kg and height ranging from $150-172 \mathrm{~cm}$. All patients were thoroughly examined preoperatively.

In the assessment room, vital parameters like pulse, blood pressure and baseline investigations like haemoglobin, urine analysis for albumin and sugar, blood sugar, urea and creatinine and Electrocardiogram were checked. Thorough examination of all the systems and airway assessment was done.

Exclusion criteria include significant co-existing diseases, long term analgesic use and contraindications to regional anaesthesia such as local infection and bleeding diathesis.

Group C: Patients received $19 \mathrm{~mL}$ of $0.5 \%$ Bupivacaine $+1 \mathrm{~mL}$ normal saline.

Group S: Patients received $19 \mathrm{~mL}$ of $0.5 \%$ Bupivacaine +50 mg of magnesium sulphate at L2 -L3 space using 17G Tuohy needle and epidural catheter at $8 \mathrm{~cm}$.

The total volume of the injected solution was $20 \mathrm{~mL}$ in both groups. The onset of sensory and motor blockade, the duration of post-operative analgesia were noted in both the groups.

In the operating theatre Boyle's apparatus, emergency drugs and airway devices were kept ready. Patients were shifted to operating table. Non-invasive blood pressure and Electrocardiogram leads were connected to the patients. Preoperative baseline systolic and diastolic blood pressure, pulse rate, oxygen saturation were recorded. Patients were cannulated with 18G intravenous needle and preloaded with 1 Litre of ringer Lactate. The patient was placed in right lateral position. The skin over the back was prepared with antiseptic solution and draped with sterile towel. After infiltrating skin and subcutaneous tissue with local anaesthetic, 17G Tuohy needle was inserted at L2-L3 space and epidural catheter inserted and placed in $8 \mathrm{~cm}$. Test dose of $2 \%$ Xylocaine with 1:200000 dilution adrenaline was given. After checking any change in pulse rate and able to dorsiflex the great toe, the position of the catheter was confirmed and the prepared solution was then injected through the catheter. Then the patient was made to lie down immediately and the time of injection of epidural anaesthetic was noted.

\section{Sensory Block}

The onset of sensory block was defined as the time between the injection of anaesthetic solution and the absence of pain at L1 dermatome level. Sensory block was assessed by loss of sensation by pinprick at L1 level. This pinpricking continued till the peak block height was reached and the time was noted. The duration of sensory block was defined as the time for regression of two segments from the maximum block height evaluate by pin prick. Sensory block was checked every $10 \mathrm{~min}$. till it reaches two segment regression levels.

\section{Motor Block}

Motor block was assessed bilaterally using Bromage scale (0: no motor block, 1: inability to raise extended legs, 2: inability to flex knees, 3 : inability to flex ankle joints). ${ }^{10}$

Assessment of motor block was started immediately after turning the patient supine and continued every minute till the patient is unable to dorsiflex the ankle joint.

\section{Vital Signs and Side Effects}

Vital parameters like systolic and diastolic blood pressure, pulse rate and oxygen saturation were recorded every $2 \mathrm{~min}$. for the first $10 \mathrm{~min}$. and thereafter every $5 \mathrm{~min}$. until the 
immediate postoperative period. Hypotension was defined as fall in systolic blood pressure more than 30\% from the baseline of systolic blood pressure or less than $90 \mathrm{mmHg}$. This was managed with intravenous ephedrine in incremental dose of $6 \mathrm{mg}$.

Bradycardia was defined as heart rate of less than $60 / \mathrm{min}$. and was planned to be managed with IV atropine in incremental doses. Respiratory depression is said to be present if respiratory rate was less then $8 / \mathrm{min}$. or oxygen saturation less than $85 \%$ on room air. This was planned to be managed with mask ventilation with oxygen. Vomiting if present was planned to be managed with Inj. Ondansetron 8 mg intravenously. Pruritis was planned to be managed with reassurance or Inj. Pheniramine maleate $22.75 \mathrm{mg}$ intravenous. Patients were shifted to post anaesthesia care unit after completion of surgery. Vital signs were recorded every $15 \mathrm{~min}$. in the first hour after surgery, $30 \mathrm{~min}$. for the next 2 hours and thereafter every hour for the next 3 hours. Patients were shifted to post-operative ward after complete resolution of motor blockade and stabilisation of blood pressure.

\section{Duration of Analgesia}

The time at which the patient complained of pain was noted and VAS Score was analysed. The duration of effective analgesia was defined as the period from the epidural injection to the first occasion when the patient complained of pain in the postoperative period.

\section{Statistical Analysis}

The collected data were analysed by using GraphPad InStat 3.06 software according to variables for chi square test and student's t-test. The results are obtained in the form of range, mean and standard deviation. The probability value ' $p$ ' of less than 0.05 was considered statistically significant.

\section{RESULTS}

Demographic data were similar in both the groups.

\begin{tabular}{|c|c|c|c|}
\hline Parameters & $\begin{array}{c}\text { Group S } \\
\text { Mean } \pm \text { SD }\end{array}$ & $\begin{array}{c}\text { Group C } \\
\text { Mean } \pm \text { SD }\end{array}$ & p value \\
\hline Age & $48.30 \pm 13.00$ & $44.60 \pm 13.21$ & 0.3233 \\
\hline Height & $165.08 \pm 5.45$ & $164.36 \pm 5.34$ & 0.639 \\
\hline Weight & $66.32 \pm 7.77$ & $65.52 \pm 7.43$ & 0.7148 \\
\hline $\begin{array}{c}\text { Onset of sensory } \\
\text { block }\end{array}$ & $5.92 \pm 0.70$ & $13.44 \pm 1.16$ & $<0.0001$ \\
\hline $\begin{array}{c}\text { Onset of motor } \\
\text { block }\end{array}$ & $12.48 \pm 2.65$ & $16.16 \pm 0.94$ & $<0.0001$ \\
\hline $\begin{array}{c}\text { Two segment } \\
\text { regression time }\end{array}$ & $145.36 \pm 4.97$ & $136.96 \pm 8.19$ & $<0.0001$ \\
\hline $\begin{array}{c}\text { Duration of } \\
\text { post-op analgesia }\end{array}$ & $231.04 \pm 12.63$ & $228.48 \pm 8.81$ & 0.41 \\
\hline \multicolumn{4}{|c|}{ Table 1. Characteristics of Study Population } \\
\hline
\end{tabular}

\begin{tabular}{|c|c|c|}
\hline & Group S & Group C \\
\hline Heart rate changes \%(Mean) & 9.84 & 9.64 \\
\hline Table 2. Percentage of Heart Rate Changes (Below the \\
Baseline Level) \\
\hline
\end{tabular}

We found the onset of sensory blockade was faster in the magnesium group ( $p$ value $<0.0001$ ). The time of onset of Motor blockade in study group was $12.48 \pm 2.670$ whereas in the control group Motor blockade was $16.16 \pm 0.943$ ( $p$ value
$<0.0001$ ) which shows that the difference is statistically significant.

The mean duration of two segment regression time in our study was $145.36 \pm 4.974$, whereas in control group was $136.96 \pm 8.19$ ( $\mathrm{p}$ value $<0.0001$ )

The duration of Post-operative analgesia was $231.40 \pm$ $12.633 \mathrm{~min}$. in our study group and $228.48 \pm 8.813$ in control group ( $p$ value $<0.41$ ) which shows that the 2 groups were not statistically significant. The probability value was detected by unpaired two-sample student ' $t$ ' test.

The incidence of side effects was similar in both the groups. There is no difference in the change in heart rate and the episode of hypotension was also similar in both the groups.

This implies that additive of magnesium sulphate to epidural Bupivacaine will quicken the onset of sensory blockade with minimal prolongation of post-operative analgesia.

\section{DISCUSSION}

The primary aim of this study was to evaluate the effect of adding magnesium sulphate to Bupivacaine in epidural anaesthesia. The safety of epidural magnesium sulphate administered in humans and animals have been well established.

NMDA receptor is an excitatory amino acid receptor that has been implicated in transmission of noxious stimulus from periphery leading to central sensitisation. ${ }^{11}$ Magnesium, a non-competitive NMDA receptor antagonist, has a role in prevention of central sensitisation from peripheral noxious stimulus. ${ }^{2}$ Whatever the route of administration, intravenous, intrathecal or epidural, the true site of action of magnesium is probably at the spinal cord NMDA receptor. ${ }^{12}$ The duration and intensity of post-operative analgesia is dependent on the degree of inhibition of NMDA receptor signal transmission. ${ }^{11}$ Hence, we conducted the study to assess the efficacy of single dose of magnesium epidurally as an adjuvant to epidural Bupivacaine Hydrochloride for reducing the onset of action of Bupivacaine and prolong the duration of analgesia.

Noxious stimulation causes the release of neurotransmitters, which attaches to different amino acid receptors, including NMDA receptor, stimulation of which results in entry of calcium into cell and causes a series of central sensitisation and long term potentiation in the spinal cord. Excitation of NMDA receptor may be of value in determining the duration of acute pain. ${ }^{13}$ Therefore, antagonist of NMDA receptor helps in the prevention and treatment of post-traumatic pain. ${ }^{14}$ Non-competitive NMDA receptor antagonist have an effect on pain when used alone, but it has also shown that they can have the analgesic properties of opioid. ${ }^{4}$ Most of the studies show that systemic administration of magnesium is accompanied by reduction in analgesic requirement and less postoperative pain. ${ }^{3}$ No study showed the physiochemical properties of magnesium in relation to its penetration to the spinal meninges, but there may be a mechanism for epidural usage, which may be related to its diffusion from the dura mater. Role of Magnesium in preventive analgesia was studied in patients who underwent abdominal hysterectomy by continuous infusion of magnesium sulphate epidurally. Before the start of anaesthesia, it was found to provide an analgesic sparing effect which improved the postoperative analgesia in a time 
period that exceeded five half litres of the drug without any increase in the adverse effects. The dose of magnesium sulphate used in this study was based on data by Tanmoy Ghatak and Girish Chandra, where $50 \mathrm{mg}$ of magnesium sulphate was added to epidural Bupivacaine. ${ }^{9}$ In their study, magnesium sulphate has quicker onset of sensory blockade. The duration of post-operative analgesia is also increased.

Tanmoy Ghatak, Girish Chandra, Anita Malik et al ${ }^{9}$ did a study on the effect of adding epidural magnesium sulphate and clonidine to bupivacaine in patients undergoing lower abdomen surgeries. All patients received $19 \mathrm{~mL}$ of epidural Bupivacaine $0.5 \%$ along with $50 \mathrm{~mL}$ of magnesium in group B, 150 mcg clonidine in saline. The onset of sensory blockade was quicker in magnesium. In group $\mathrm{C}$, there was prolongation of duration of anaesthesia and sedation with lower VAS score. The study explained the probable reason for quicker onset of sensory blockade in magnesium group that is; it is a NMDA receptor antagonist. Magnesium also has the property of anti-nociceptive effect in animal models. There are no additional side effects in both groups.

AA Yousef and Y M Amr et al ${ }^{15}$ demonstrated the effect of adding magnesium sulphate to epidural Bupivacaine and Fentanyl in elective caesarean section using combined spinalepidural anaesthesia. The group that received magnesium has faster onset of sensory block and greater motor block and muscle relaxation $(\mathrm{p}<0.05)$ and also later onset of postoperative pain. There is no difference in hypotension, nausea and vomiting.

R. Arcinoni and S. Palmisami et al ${ }^{16}$ conducted a study of giving intrathecal and epidural magnesium sulphate supplementation of spinal anaesthesia to patients undergoing orthopaedic surgeries. In patients receiving spinal anaesthesia with combined intrathecal and epidural magnesium sulphate, there is significant reduction in postoperative analgesia requirement. Magnesium sulphate alters pain processing and reduces the induction and maintenance of central sensitisation by blocking the NMDA receptor in the spinal cord.

A. Bilir and S. Gulec et al conducted a study of 50 patients undergoing hip surgery who were enrolled to receive either Fentanyl (F) or Fentanyl plus magnesium sulphate (FM) for 24-hour epidural analgesia. Magnesium has anti-nociceptive effects in animal and human models of pain, coadministration of magnesium for post-operative epidural analgesia results in a reduction in Fentanyl consumption without any side effects.

In our study group, the time of onset of sensory blockade was $5.92 \pm 0.702 \mathrm{~min}$., whereas in control group it was 13.44 \pm 1.158 ( $p$ value $<0.0001$ ), which shows that the difference is statistically significant in the onset time. The addition of magnesium sulphate has definitely decreased the sensory onset time.

The results correlate the study of T. Ghatak and G. Chandra of addition of epidural magnesium sulphate to Bupivacaine to reduce the time of onset of sensory blockade. 9

The change in Heart rate was $9.84 \%$ in our study group whereas in control group it was $9.64 \%$ which shows there is no significant change. The usage of Ephedrine also does not produce significant changes.

Our study was limited by the absence of dose response of epidural magnesium for post-operative analgesia. In the absence of literature regarding body weight base dosage of epidural magnesium, we used $50 \mathrm{mg}$ of magnesium sulphate with $19 \mathrm{~mL}$ of $0.5 \%$ Bupivacaine as bolus in our study. The result of present randomised controlled clinical trials raises the need for more clinical studies regarding various dosage regimen of epidural magnesium.

\section{CONCLUSION}

In our study, we found the onset of sensory blockade was faster in the magnesium group. The duration of postoperative analgesia was slightly prolonged in the study group. This study concludes that epidural magnesium sulphate when added to Bupivacaine will shorten the onset of sensory blockade significantly in patients undergoing elective lower abdominal surgeries without increasing the incidence of side effects.

\section{REFERENCES}

[1] Sirvinskas E, Laurinaitis R. Use of magnesium sulfate in anaesthesiology. Medicine (Kaunas) 2002;38(7):695-8.

[2] Begon S, Pickering G, Eschalier A, et al. Magnesium increase morphine analgesic effect in different experimental models of pain. Anaesthesiology 2002;96(3):627-32.

[3] Kroin JS, McCarthy RJ, Von Roenn N, et al. Magnesium sulfate potentiates morphine antinociception at the spinal cord level. Anesth Analg 2000;90(4):913-7.

[4] Buvanendran A, McCarthy RJ, Kroin JS, et al. Intrathecal magnesium prolongs fentanyl analgesia: a prospective, randomized, controlled trial. Anesth Analg 2002;95(3):661-6.

[5] Koinig H, Wallner T, Marhofer P, et al. Magnesium sulfate reduces intra- $\&$ post-operative analgesia requirements. Anaesth Analg 1998;87(1):206-10.

[6] Lee AR, Yi HW, Chung IS, et al. Magnesium added to bupivacaine prolongs the duration of analgesia after interscalene nerve block. Can J Anaesth 2012;59(1):21-7.

[7] Woolf CJ, Thompson SW. The induction and maintenance of central sensitization is dependent on $\mathrm{N}$-methyl-D-aspartic acid receptor activation: implications for the treatment of post-injury pain hypersensitivity states. Pain 1991;44(3):293-9.

[8] Akutagawa T, Kitahata LM, Saito H, et al. Magnesium enhances local anesthetic nerve block of frog sciatic nerve. Anesth Analg 1984;63(2):111-6.

[9] Ghatak T, Chandra G, Malik A, et al. Evaluation of the effect of magnesium sulphate vs. clonidine as adjunct to epidural bupivacaine. Indian J Anaesth 2010;54(4):308-13.

[10] Bromage PR. A comparison of the hydrochloride and carbon dioxide salts of lidocaine and prilocaine in epidural analgesia. Acta Anaesthesiol Scand Suppl 1965;16:55-69.

[11] Tramer MR, Schneider J, Marti RA, et al. Role of magnesium sulfate in postoperative analgesia. Anaesthesiology 1996;84(2):340-7.

[12] Bilir A, Gulec S, Erkan A, et al. Epidural magnesium reduces postoperative analgesia requirement. $\mathrm{Br} \mathrm{J}$ Anaesth 2007;98(4):519-23. 
[13] Ko SH, Lim HR, Kim DC, et al. Magnesium sulphate does not reduce postoperative analgesia requirements. Anaesthesiology 2001;95(3):640-6.

[14] Ozalevli M, Cetin TO, Unlugenc $\mathrm{H}$, et al. The effect of adding intrathecal magnesium sulphate to bupivacaine-fentanyl spinal anaesthesia. Acta Anaesthesiology Scand 2005;49(10):1514-9.

[15] Yousef AA, Amr YM. The effect of adding magnesium sulphate to epidural bupivacaine and fentanyl in elective caesarean section using combined spinalepidural anaesthesia: a prospective double blind randomised study. Int $\mathrm{J}$ Obstet Anesth 2010;19(4):401-4.
[16] Arcioni R, Palmisani S, Tigano S, et al. Combined intrathecal and epidural magnesium sulfate supplementation of spinal anesthesia to reduce postoperative analgesic requirements: a prospective, randomized, double-blind, controlled trial in patients undergoing major orthopedic surgery. Acta Anaesthesiol Scand 2007;51(4):482-9. 